\title{
Acute Aggression After Progesterone Discontinuation in a Young Female
}

Mujeeb U Shad ( $\square$ mujeebushad@gmail.com )

Touro University Nevada.

\section{Case report}

Keywords: Female, aggression, progesterone, discontinuation

Posted Date: December 15th, 2020

DOI: https://doi.org/10.21203/rs.3.rs-126161/v1

License: (c) (i) This work is licensed under a Creative Commons Attribution 4.0 International License. Read Full License 


\section{Abstract}

\section{Background:}

Although cyclical changes in progesterone activity have been linked with various psychiatric symptoms, such as anxiety, mood, and premenstrual dysphoria, less is known about the effects of contraceptive use of progesterone and behavioral aggression.

\section{Case Presentation:}

We report a case of a 23-year old hospitalized African female diagnosed with complex post-traumatic stress disorder (PTSD), bipolarity and history of alcohol use disorder, who developed significant behavioral aggression within a short time of removing her progestin (progesterone) implant. The association between abrupt behavioral deterioration and discontinuation of the contraceptive implant was further supported by resolution of patient's aggression after 3 days of starting a long-acting progesterone contraceptive, medroxyprogesterone acetate, instead of the progestin implant to prevent non-adherence. This, to our knowledge, is the first case to document relationship between discontinuation of a progesterone contraceptive and aggressive behavior in a patient with significant trauma and psychiatric history.

\section{Discussion \& Conclusion:}

This may be the first documented case of behavioral aggression in a young African female after removal of a progesterone implant followed by resolution of aggression after initiating a long acting progesterone injection. Although several studies, mostly in animals, have shown a link between progesterone levels and aggression, there are no reports of aggression concerning contraceptive use of progesterone. Such aggression may be rare in healthy subjects but may be more common in a psychiatrically vulnerable patient with significant trauma history.

\section{Background}

The psychiatric effects of progesterone and its metabolite allopregnanolone are well-known in anxiety (1), premenstrual syndrome, dysmenorrhea (2), and post-partum depression $(3,4)$. However, the evidence for progesterone's role in behavioral aggression is not as clear and is primarily based on animal data (5). Although the studies in post-partum depression were not designed to investigate aggression, the authors provided plausible mechanism of action behind brexenalone's efficacy in post-partum depression $(3,4)$. Brexenalone, an intravenous formulation of allopregnanolone, is a positive allosteric modulator of inhibitory GABA-A receptors (3). Being a PAM for GABA-A receptors, brexenalone increases the inhibitory feedback from GABA interneurons to dampen the excessive and excitotoxic glutamatergic activity observed during post-partum depression $(6,7)$. The glutamatergic dysregulation has been associated across other symptom domains, including psychosis (8) and behavioral aggression (9). Thus, it is 
possible to experience behavioral dysregulation in response to glutamate surge following abrupt discontinuation progesterone contraceptives.

\section{Case Presentation}

The patient is a 23-year-old single African refugee female with complex PTSD, unspecified bipolar disorder, and alcohol use disorder in early remission, who was initially hospitalized in a community hospital for suicidal thoughts and alcohol intoxication, followed by readmission to a state psychiatric facility for severe agitation. The medical records revealed similar suicidal behavior in the recent past after excessive alcohol intake, resulting in repeated emergency visits at a local hospital. Based on the medical records, patient developed complex PTSD after her family was killed in front of her eyes during ethnic violence. The patient was reported to suffer from flashbacks, nightmares, and panic attacks, particularly when she heard any gunshots. However, there was no history of psychosis. The severity of her PTSD and alcohol intoxication was the main reason that the patient visited the local emergency department several times before she had to be hospitalized, first to a community hospital, later to be transferred to a state psychiatric facility for further treatment. Medications at admission included fluoxetine, $60 \mathrm{mg} /$ day, prazosin $2 \mathrm{mg} /$ day, and perphenazine $8 \mathrm{mg}$ two times/day, later augmented with divalproex sodium $500 \mathrm{mg}$ two times day (recent levels $91 \mathrm{mcg} / \mathrm{mL}$ ) to address bipolarity. However, patient was found to significant extrapyramidal symptoms and hyperprolactinemia, both of which resolved after patient was gradually cross-titrated from perphenazine to quetiapine $300 \mathrm{mg}$ at bedtime and became stable enough to initiate discharge planning. However, a couple of weeks before her potential discharge, patient secretly removed her progestin implant, as she wanted to become pregnant despite being educated about the teratogenic effects of divalproex sodium. This was followed by extreme aggression towards staff and other patients as reflected by seclusion and restraint events every day for ten consecutive days. Initially the treatment team failed to find any reason for this sudden onset of aggressive behavior without any changes in patient's medication or environment, but a few days later, staff discovered the removal of her progestin implant after finding bloodstained gauze in patient's room. When confronted, patient admitted

taking out the implant. At this time, the patient was started on a long-acting injectable (LAI) progesterone contraceptive, medroxyprogesterone acetate, to prevent future nonadherence. Within three days, patient returned to baseline non-aggressive behavior and was eventually discharged from the state psychiatric facility after a week.

\section{Discussion \& Conclusions}

This, to our knowledge, is the first case to report acute aggression after the discontinuation of progesterone (progestin) implant followed by resolution of aggression within three days of initiating medroxyprogesterone acetate (progesterone LAl) in a young African female. This onset of action is consistent with the time medroxyprogesterone acetate required to change cervical mucus (10). Because progesterone can easily cross the blood-brain barrier, the central effects may be seen in a similar timeline as the peripheral effects. It is interesting to note therapeutic levels of divalproex sodium did not prevent 
sudden onset of behavioral aggression in this patient, which suggests that allosteric modulation may differ with the direct GABAergic effects of valproic acid. The diagnosis of complex posttraumatic stress disorder (PTSD) may also be of relevant to the acute aggression observed in this patient. Decreased levels of progesterone have been associated with fear, learning deficits, and higher PTSD symptomatology, as well as heightened intensity and the duration of adrenergic response under stress (11). In addition, individuals with low plasma GABA levels are also prone to develop PTSD after traumatic experience (12). Furthermore, administration of progestin implant may have boosted mood-stabilizing effects of valproate in our patient, who was diagnosed with unspecified bipolar disorder. This view is supported not only by the mood stabilization reported with progesterone (13), but also improvement in bipolar depression with pregnenolone in a clinical trial (14). With regard to alcohol, the patient was sober since her admission for about three months at the state hospital facility, which makes alcohol a less likely contributor to aggression in this patient.

The findings from this study are based on a single patient and should be interpreted with caution. However, clinicians should consider complex psychiatric effects of progesterone and its metabolite, allopregnanolone, beyond contraception, especially in patients with a complex psychiatric history. Careful counseling and close follow-up are recommended for patients with psychiatric disorders, such as premenstrual dysphoric disorder, seeking these contraceptive methods.

\section{Declarations}

- Ethics approval and consent to participate: This case report is based on a single patient's clinical observations and retrospective analysis of her chart. This case report does not have any personal health identification information.

- Consent for publication: verbal consent was obtained

- Availability of data and materials: no formal data were created for this single patient case report

- Competing interests: none

- Funding: none

- Authors' contributions: The only contributing and corresponding author, Mujeeb U. Shad conceived the idea of presenting this interesting case report and drafted the manuscript himself. MS reviewed the final version of the manuscript and approved it.

- Acknowledgements: none

\section{References}

1. Reynolds TA, Makhanova A, Marcinkowska UM, Jasienska G, McNulty JK, Eckel LA, et al. Progesterone and women's anxiety across the menstrual cycle. Horm Behav. 2018;102:34-40. 
2. Glick ID, Bennett SE. Psychiatric complications of progesterone and oral contraceptives. J Clin Psychopharmacol. 1981;1(6):350-67.

3. Kanes SJ, Colquhoun H, Doherty J, Raines S, Hoffmann E, Rubinow DR, et al. Open-label, proof-ofconcept study of brexanolone in the treatment of severe postpartum depression. Hum Psychopharmacol. 2017;32(2).

4. Meltzer-Brody S, Colquhoun H, Riesenberg R, Epperson CN, Deligiannidis KM, Rubinow DR, et al. Brexanolone injection in post-partum depression: two multicentre, double-blind, randomised, placebocontrolled, phase 3 trials. Lancet (London, England). 2018;392(10152):1058-70.

5. Goymann W, Wittenzellner A, Schwabl I, Makomba M. Progesterone modulates aggression in sex-role reversed female African black coucals. Proc Biol Sci. 2008;275(1638):1053-60.

6. Gerhard DM, Pothula S, Liu RJ, Wu M, Li XY, Girgenti MJ, et al. GABA interneurons are the cellular trigger for ketamine's rapid antidepressant actions. J Clin Invest. 2020;130(3):1336-49.

7. Li YF. A hypothesis of monoamine (5-HT) - Glutamate/GABA long neural circuit: Aiming for fastonset antidepressant discovery. Pharmacol Ther. 2020;208:107494.

8. Lieberman JA, Girgis RR, Brucato G, Moore H, Provenzano F, Kegeles L, et al. Hippocampal dysfunction in the pathophysiology of schizophrenia: a selective review and hypothesis for early detection and intervention. Molecular psychiatry. 2018;23(8):1764-72.

9. Craig MC, Mulder LM, Zwiers MP, Sethi A, Hoekstra PJ, Dietrich A, et al. Distinct associations between fronto-striatal glutamate concentrations and callous-unemotional traits and proactive aggression in disruptive behavior. Cortex. 2019;121:135-46.

10. Petta CA, Faundes A, Dunson TR, Ramos M, Delucio M, Faundes D, et al. Timing of onset of contraceptive effectiveness in Depo-Provera users. II. Effects on ovarian function. Fertil Steril. 1998;70(5):817-20.

11. Garcia NM, Walker RS, Zoellner LA. Estrogen, progesterone, and the menstrual cycle: A systematic review of fear learning, intrusive memories, and PTSD. Clin Psychol Rev. 2018;66:80-96.

12. Vaiva G, Thomas P, Ducrocq F, Fontaine M, Boss V, Devos P, et al. Low posttrauma GABA plasma levels as a predictive factor in the development of acute posttraumatic stress disorder. Biological psychiatry. 2004;55(3):250-4.

13. Belelli D, Bolger MB, Gee KW. Anticonvulsant profile of the progesterone metabolite 5 alpha-pregnan3 alpha-ol-20-one. Eur J Pharmacol. 1989;166(2):325-9.

14. Brown ES, Park J, Marx CE, Hynan LS, Gardner C, Davila D, et al. A randomized, double-blind, placebocontrolled trial of pregnenolone for bipolar depression. Neuropsychopharmacology : official publication of the American College of Neuropsychopharmacology. 2014;39(12):2867-73. 